This item was submitted to Loughborough's Research Repository by the author.

Items in Figshare are protected by copyright, with all rights reserved, unless otherwise indicated.

\title{
Fifty years of UK research in information science
}

PLEASE CITE THE PUBLISHED VERSION

PUBLISHER

Sage for the Chartered Institute of Library and Information Professionals

LICENCE

CC BY-NC-ND 4.0

REPOSITORY RECORD

Meadows, Jack. 2019. "Fifty Years of UK Research in Information Science". figshare. https://hdl.handle.net/2134/3125. 
This item was submitted to Loughborough's Institutional Repository by the author and is made available under the following Creative Commons Licence conditions.

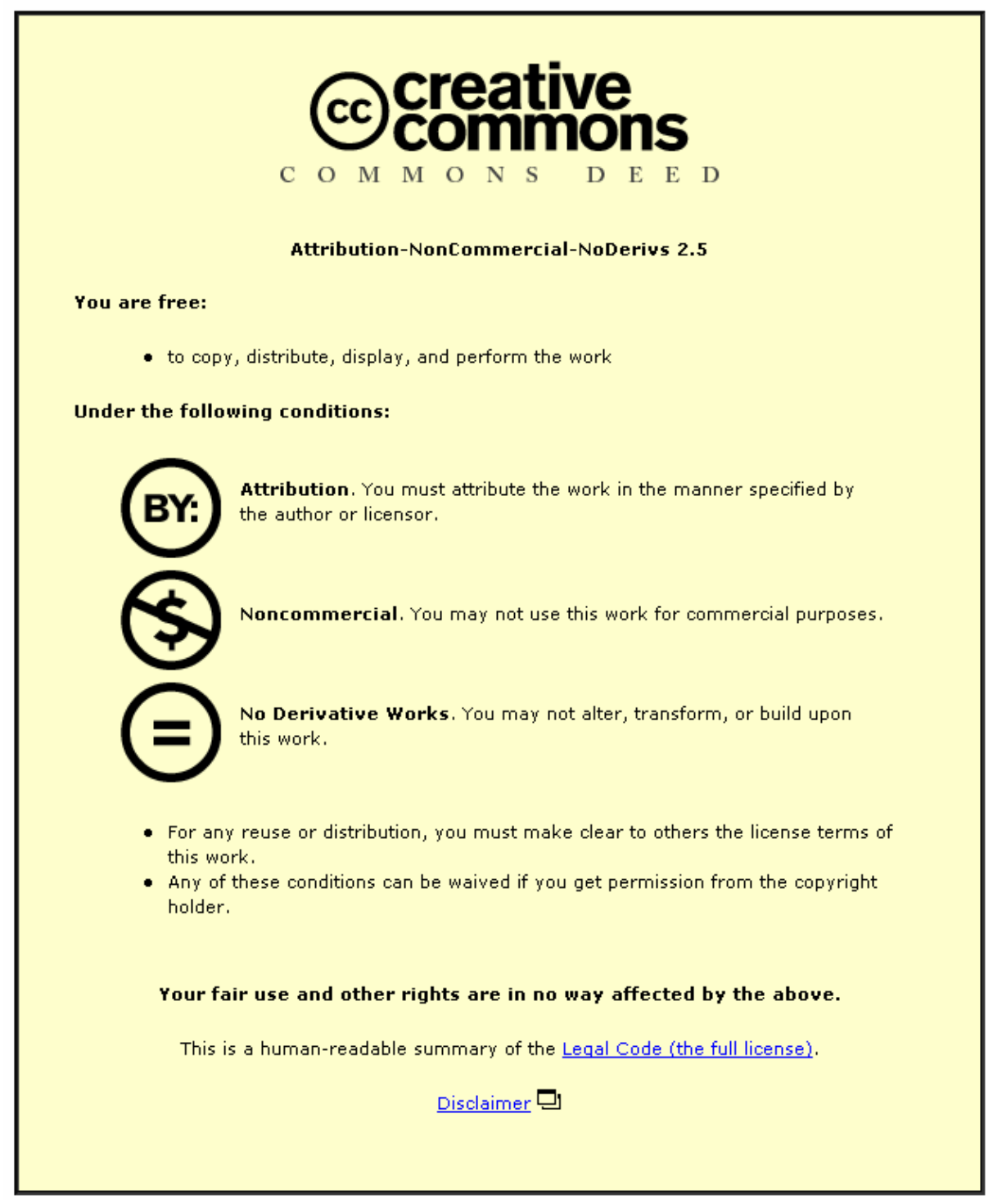

For the full text of this licence, please go to: http://creativecommons.org/licenses/by-nc-nd/2.5/ 


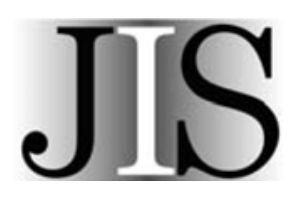

\title{
Fifty Years of UK Research in Information Science
}

\author{
Jack Meadows $^{1}$ \\ Department of Information Science, Loughborough University, UK
}

\begin{abstract}
An attempt is made to discern the main research themes in British information science over the past half-century. Within these themes, emphasis is placed on research in the UK that has had some impact on the international information science community. The major factors that have influenced information science research in the UK are also briefly considered.
\end{abstract}

\section{Introduction}

Research that clearly falls under the 'information science' heading was already being carried out in the UK in the first half of the twentieth century, though the volume of such research was small. It was in the second half of the century that systematic research in this field - and, indeed, the name, itself - became fully established, and that the amount of research began to grow rapidly. Today, information science has matured to the stage where even the study of its history has become a legitimate topic for research [1]. A definition of information science acceptable to everyone has always proved difficult to find, from the early days right up to the present. There has, however, been greater agreement on what are the important topics that information scientists should study: most of the topics mentioned in the early days are still regarded as important today, though relative emphases have changed. The development of information science research - as with most science and social science subjects - is reflected reasonably well by the changing nature of the research papers published in its leading journals. So I have used these as my main guide to UK research over the past half century.

The UK is fortunate in possessing a number of internationally recognised journals that cover library and information science research. These, and especially the Journal of Information Science and the Journal of Documentation, have published a wide variety of

${ }^{1}$ Correspondence to: Jack Meadows, Department of Information Science, Loughborough University, LE11 $3 T U$, email: a.j.meadows@lboro.ac.uk 


\section{Jack Meadows}

research by British information scientists over the past fifty years. The contents of the Journal of Information Science cover all areas of the field and little that is not relevant, but it only started publication in 1979. The Journal of Documentation gives better time coverage, since it goes back beyond the beginning of the period discussed here. It, too, covers all areas of information science, but also includes other topics, more especially relating to libraries. Both journals have always been held in high regard by researchers in the field of information science. Consequently, an analysis of the two together probably provides a reasonable picture of the range of information research in the UK and how it has developed with time (though the papers published by these journals are not, of course, restricted to UK authors only). In examining these journals (along with reading a number of historical reviews and reminiscences), I have tried to look mainly for themes, rather than for individual articles or authors. Correspondingly, the references cited mainly represent examples of a theme, rather than constituting the sole essential reading in that area. In other words, different papers and different authors could often have been cited to illustrate the research theme under discussion. There is one proviso. For research to be labeled as important, it must be recognised as such internationally. I have therefore primarily quoted UK research that has been well cited abroad as well as at home.

\section{Major topics in information science}

What, then, have been the significant themes? A survey of forty LIS journals published over the period 1965-1985 found that information retrieval - defined in fairly broad terms dominated their coverage as measured in terms of number of articles published [2]. This was followed fairly closely by studies of library and information services. Between them, these two topics accounted for over half of all the research reported throughout the whole period: no other area breached the ten percent barrier in terms of relative contribution. It is interesting to examine the coverage of topics in the Journal of Information Science from its birth to the present day, and to compare it with these figures using the same kind of categorisation. The dominant theme is again information retrieval. But now it is closely followed by research in the general area of information seeking. Research on library and information services is much less important. (The difference is mainly due to the inclusion in the earlier survey of a large number of library journals.) Behind the two main themes - but still representing significant coverage come studies in the fields of bibliometrics and communication. Bibliometrics has been a regular topic from the start, but articles on communication studies have increased with time. A comparison with the contents of the Journal of Documentation, including the period before the Journal of Information Science appeared, suggests that these four themes - information retrieval, information seeking, communication, and bibliometrics - provide a reasonable basis for looking at how UK research in information science has developed over the past 50 years. 


\section{Jack Meadows}

\section{Information retrieval}

The present issue contains other contributions that deal with aspects of information retrieval in more detail. The discussion here simply aims at noting developments in the UK that have been important outside the country, as well as within. One that undoubtedly falls into this category occurred right at the beginning of our 50-year period. This was the series of Cranfield experiments that began in the late 1950s. The first set of experiments evaluated and compared retrieval of information from different kinds of databases. The second looked at the use of alternative indexing languages [3]. These studies emphasised recall and precision as important parameters in such evaluation, since they allowed numerical comparison of the different systems under assessment. This pioneering work naturally led to the idea of improved experiments, especially as electronic data handling became more sophisticated. In the UK, there was considerable discussion of the need for improved test collections for use in a new range of experiments [4]. In the event, this development did not occur until the early 1990s, when the TREC [Text REtrieval Conference] exercise was initiated in the USA. The emphasis here was on large-scale retrieval using a vast collection of documents. In typical American style, teams of specialists in information retrieval have competed against each other to see who can obtain the best retrieval results. The exercise has had a major impact, since it has been repeated year by year and the results widely disseminated. Although the bulk of the teams are American, a range of other countries have been involved and the UK contribution has been significant [5].

Methods of retrieving information have typically been discussed by specialists in the field long before they have been implemented in practice. It is only in recent years that the world at large has caught up in terms of day-to-day application. At the theoretical level, the input by UK researchers has been particularly significant. One reflection of this can be found in the widely read texts that they have produced $[6,7,8]$ The idea of using Boolean operators for searching had already been mentioned by Bradford in his pioneering text on documentation [9]. It was commented on again by Fairthorne in 1962 in the context of the developing use of computers [10]. But it has the drawback that the retrieved documents are all regarded as being of equal relevance (they are usually presented to users simply in terms of date of publication). One way round this has been to give the various search terms different weightings. An important step forward here was the introduction of an automatic weighting scheme based on 'inverse document frequency' [11], which subsequently became a standard approach. It depended on an understanding of the likely frequencies of different words in the documents concerned. A computer using this system could now output a list of references in order of likely relevance to the user. Another significant step forward in the early 1970s was the demonstration that automatic clustering of documents could be implemented as part of the search process in order to improve the relevance of the items retrieved [12]. A few years later came the demonstration that ranking based on probable relevance was the optimum way of ordering the results of retrieval [13].

The word 'relevance' constantly appears in information retrieval, but its interpretation has been a continual matter of dispute. In principle, retrieved information is relevant if the user who posed the query says that it is. One problem with the Cranfield experiments was that 


\section{Jack Meadows}

relevance assessments were not made by genuine end-users, so there has since been an increasing interest in involving users directly in the evaluation of retrieved information. Such relevance feedback can be obtained in various ways (eg. by asking the user to select the most relevant documents, and using these as the basis for another round of retrieval). One of the most successful developments of such an interactive approach is the Okapi project, which began in the early 1980s, moving to the City University in 1989 [14]. The design has been improved over the years, and has proved highly successful in the TREC competition. Some of the improvements have been widely copied. The growing interest in interaction with users has led to an increasing cross-fertilization between research in information retrieval and in information-seeking [15]. The actual approach followed in information retrieval obviously depends in part on the type of information involved. The TREC experiments, for example, included retrieval of graphics as another track alongside text. One specialised area of information retrieval to which the UK has made a significant contribution relates to chemical compounds. Work on retrieval of chemical information began at Sheffield in the 1960s, and has expanded in subsequent decades. The work there on the computer-based retrieval of chemical structures has been especially valuable. It has helped provide a basis for the now rapidly expanding field of chemoinformatics (with subsequent input to the even larger field of bioinformatics) [16].

The definition of information retrieval used in [2] includes cataloguing, classification, indexing and database creation along with the information retrieval activity, itself. These different retrieval aids have varied in their relative importance over the past 50 years, but it has always been clear that they are linked together. The Okapi project, for example, was originally designed as an online public access catalogue [OPAC] which was later developed to search scientific abstracts. One spin-off from the post-war concern with information, in part stimulated by the Royal Society's interest, was the formation of a Classification Research Group in 1952. The group was therefore already going strong at the start of our 50-year period, and its interest in classification covered all types of information. Its members were, for example, concerned with the major post-war advances in biomedical classification. It was evident from the start that classification and information retrieval were interlinked - indeed, future prospects for the two were discussed at length in a conference on 'Classification for information retrieval' held at Dorking fifty years ago. Similarly, the construction of thesauri was accepted from early on as a standard part of retrieval [17]. The year before the Institute of Information Scientists [IIS] was founded saw the origin of the Society of Indexers - another reflection of the growing interest in different methods of indexing. So all the retrieval components were there from the start, but they tended initially to be developed in their own ways - perhaps because the interest of information scientists and librarians in these topics often differed in emphasis. The rapid growth in computer-based handling of information over the past two decades has seen an increased level of linkage between the various activities: not least because the growth of internet browsing by end-users has meant a change of emphasis in terms of information retrieval. Nowadays, a web search engine is likely to include anything from the most recent work on information retrieval to an input from recent ideas about classification and thesauri. The ever-growing emphasis on all kinds of information retrieval means that the whole field has now become a mainline research topic. From being a characteristic component of 


\section{Jack Meadows}

information science, it has also become a widely investigated research topic in computer studies and related fields. As a consequence, it is becoming increasingly difficult to determine what particular input to information retrieval comes from researchers in information science.

\section{Information seeking}

The second major category of information research noted above was information seeking, including the whole field of user studies. As with information retrieval, the topic is covered elsewhere in this issue, so I will again concentrate on work that has evoked international, as well as national interest. Surveys of users had been carried out in library contexts before they became an important feature of information studies. In the latter area, the application of such surveys in the UK was stimulated by the work of Bernal and Urquhart on users of science information in the early post-war years. The work of both investigators was reported at the famous conference on scientific information organised by the Royal Society in 1948. The Royal Society interest in information continued, leading on to an in-depth survey of researchers' activities across the sciences in the early 1980s [18]. The results indicated an interesting dichotomy - British scientists were typically conservative in terms of usage patterns, yet seemed to welcome increased automation of information seeking. This survey was relatively widely targeted. Most user studies - and there have been many of them over the past 50 years - have been aimed at more specific groups or environments. Though science, technology and medicine [STM] has been a favoured area for user studies, most other fields have been the subject of some investigation. For example, information use in the social sciences received attention from the beginning [19], and was the subject of one of the largestscale studies carried out in the earlier years [20]. A further major study at the end of the 1970s reflected a general trend in survey work that has emerged over the past few decades - a growing emphasis on a qualitative, rather than a quantitative approach [21]. Most user studies have been on a smaller scale and, though the results may be of potentially wider application, they have sometimes been limited by the relatively small number of respondents involved. In more recent years, usage studies have particularly concentrated on the use of electronic resources. One great advantage of these is that the characteristics of the usage - if not always of the user - can be derived from statistics provided by the system itself. Consequently, the activities and habits of large numbers of users can be examined simultaneously [22].

If usage is one side of the coin for information scientists, information management is the obverse. This has been accepted as a basic component of information science from the start, though originally it often came under the heading of 'records management'. The growth of information technology during the 1970s expanded the possibilities for the more efficient management of information, and technological change has continued to have an impact ever since. By the end of the 1980s, information management had been identified in the UK as an important growth area in information science [23], with a consequent increase in the research attention that it received. The UK was obviously not unique in this. Nevertheless, a survey of information research in Western Europe in the 1990s showed that the UK was in the lead in terms of information management research [24]. With the growth of computerisation, research 


\section{Jack Meadows}

into the management of libraries and the broader management of information sources increasingly overlapped. For example, studies of how to evaluate systems and organisations and how to implement performance measures developed in parallel for both. Information management has now become a regular part of institutional activities, as indicated, for example, by the action of the Joint Information Systems Committee [JISC] in its recent launch of an online information management kit as a standard package for use in higher and further education institutions. The appearance of knowledge management in the 1990s engendered rather more controversy. In part, this was due to the varying definitions of what knowledge management was about, since it often seemed that what was being managed was information, rather than knowledge. Indeed, views on this matter among British information scientists have ranged from considerable doubts concerning its validity [25] to the construction of lengthy textbooks on the topic [26].

As noted above, studies of information needs and usage have evolved with the passage of time. The initial emphasis was on surveys involving quantitative or semi-quantitative approaches (and these are still commonplace). In recent decades, qualitative approaches have become increasingly popular. There has been a similar shift in emphasis in the social sciences as a whole. The two trends are related in the sense that the methodologies used in information science have often been adopted or adapted from those developed for investigations in sociology and related subjects. An example is soft systems methodology - an approach devised originally for business studies in the UK - which has been used in a number of information science projects [27]. There has also been a shift from looking at the usage itself to looking at the methods whereby users actually seek for information. In this area, there have again been valuable contributions by UK practitioners. One model, in particular, which looks at the links between information needs and information-seeking behaviour, has been widely used, both in its original form and with subsequent updating [28].

Research interest in recent decades has concentrated especially on information-seeking aspects, so adding greater sophistication to the relatively simple approach taken in classical information retrieval. A proper understanding of human information seeking and retrieval is now seen as involving an examination of cognitive factors. For example, one early model which attracted considerable attention - hinged on the point that the actual information needs of potential users are not necessarily known [29]. What can be ascertained is the users' perceptions of where they have an information problem: retrieval entailed studying these 'anomalous states of knowledge'. Since perceptions can change as retrieval progresses, the implication of such models is that retrieval systems must allow a high level of interactive input from the information seeker. The detailed characteristics of the information-seeking process will, of course, depend partly on the characteristics and background of the end-user concerned. However, comparative studies of information seeking by scientists and social scientists have revealed considerable similarities in the basic activities involved, though these may be affected by the limitations of the information system used [30]. The growing desire for flexibility in handling retrieval problems soon suggested the possibility of employing techniques from the developing world of artificial intelligence. This has led to the construction of a number of intelligent interfaces for use in online searching, including valuable work in the UK [31]. As yet, most of the systems that have been devised have remained experimental. 


\section{Jack Meadows}

The rapidly expanding part played by computers in information handling has meant that information science research has come increasingly to overlap with work in computer science, particularly in the area of human-computer interaction [HCI]. This marriage has been evident, for example, in the search for new approaches to training in information skills and in the production of user-friendly interfaces. In looking for understanding of these topics, information science researchers in British universities have often targeted their own students. In part, this is because the students provide an easy, and relatively docile, target group to examine; but it is also, in part, because an important motivation for such research has been the question of how best to provide computer-based and computer-assisted learning for the student population [32]. At the same time as this rapprochement between computer scientists and information scientists has been occurring, the computerisation of libraries has led to a new confluence of interest between library researchers and information scientists. This is reflected most obviously in the development of OPACs, where information science concerns with retrieval have equally become central to the activities of traditional libraries. Online catalogues began to supplement card catalogues in the 1970s. By the 1980s, their capabilities had expanded to the extent that they could enhance the range of functions of a card catalogue. But it took time, and improved design, before OPACs became popular [33]. In fact, research on OPACs underlined the point made above - the need for greater flexibility and feedback when systems are being used by novices (in terms of information seeking). The overlap between information science interests and library interests has grown as libraries have moved away from their traditional role as guardians of the printed heritage to the handling of a hybrid mixture of printed and electronic information. Indeed, discussions of libraries of the future now typically concentrate on the role of the digital library with traditional aspects relegated to a subordinate role [34]. It is reasonable to expect that the overlap of interests that has occurred between information science and libraries in recent years will continue to grow in the future.

\section{Other themes}

The growth in information science research over the past 50 years has been paralleled by the growth of research into communication studies. Information research usually revolves round some pool of information: the questions asked tend to be about how the contents of the pool should be handled. The information in the pool often consists of formal sources - more often than not articles in journals. Communication research is more often concerned with the interactive exchange of information, and the information involved may well be transmitted informally - for example, via conversations. As this suggests, the gap between the two research fields is not vast, and information scientists have often strayed into research on communication. Thus, a number of studies were carried out during the 1960s and 1970s - some in the UK - into the importance of informal communication as a method of acquiring additional information alongside that available from formal sources [35]. Communication research has actually ranged widely in terms of scope. An influential text on the topic was published by a British author right at the beginning of our 50-year period, and it covered everything from philosophy to electrical engineering [36]. A number of the ideas developed in studies of 


\section{Jack Meadows}

communication have proved valuable in information science research. One such is insight into how information diffuses through a community; another is the concept of the invisible college' [37]. The growth of computer-based communication, especially email, has both increased the importance of informal communication over the past two decades and made the borderline between formal and informal communication less easy to define. Consequently, the distinction between information and communication studies has also become increasingly blurred.

Traditionally, the communication chain for formal publications has been visualised as a sequence that starts with the author, continues through the publisher and the library (or information centre), and ends with the reader (or information user). The primary concern of information scientists has been with the last two steps in this chain. However, in terms of information content, this division is not always clear-cut. To paraphrase a Tom Lehrer song, flows of information may be compared with the flow in a sewage system - what comes out at the end depends on what is put in at the start. Consequently, some studies of information handling by publishers and authors have been carried out by information scientists from the beginning. Since the researchers' interest has usually focused on R\&D work, it is journal publishing that has been examined in most detail. One common characteristic of such journals is that they rely on some kind of quality control mechanism to decide on their content. The activities involved, especially the process of refereeing, have been the subject of numerous studies, including some important ones carried out in the UK [38]. The questions examined have ranged from subject differences in refereeing to the existence of bias in referees' assessments. The overall result has been to confirm the value of quality control for journal contents while also emphasising its limitations [39].

The growth of the digital world has made it necessary to re-examine the workings of the information chain. Over the last two decades, electronic journals have moved from the experimental stage to a major branch of publishing. The first successful experiment was actually carried out in the UK in the early 1980s - the BLEND [Birmingham and Loughborough Electronic Network Development] programme [40]. It was established by HCI researchers, rather than information scientists, and provided a further stimulus for the latter to use HCI methodology as one of their tools. It was apparent from the start that electronic journals created problems for the operation of the traditional communication chain; or, to put it in more general terms, the challenge was to evaluate all the impacts on information handling that a move from a print medium to an electronic medium might entail. The main early concern in information science was with the future of journals, and this has led to a range of surveys and experiments in the last two decades [41], but interest is now broadening to cover almost any type of information source. Uncertainties regarding the future roles of both publishers and libraries has emphasised the need for information scientists to consider the whole of the publication chain. An obvious example, which has involved a number of information scientists, has been the debate - often controversial - over the provision of open access [OA] to researchers' publications. All parts of the chain - authors, publishers, librarians and users have been involved in this discussion. The original simple idea was that researchers should put up the papers they had written on their websites, as well as publish them in printed form; but this has been considerably elaborated over the past ten years. In consequence, a growing 


\section{Jack Meadows}

number of studies have been looking at both the methods of implementing OA and its consequent impact [42]. The UK has been an important focus for the OA debate, since the main proponent of $\mathrm{OA}$ and the website he runs have been sited at Southampton University [43]. One essential aspect of the OA debate has been the role of copyright. For example, who should claim the copyright in research papers, and so have the right to circulate them via the Internet - authors, their institutions, or publishers [44]? Interest nowadays has broadened from copyright to intellectual property law as a whole. In the UK, the latter has come to the fore because EU legislation in this area - which differs from the traditional British approach - has been developing. The question now is how such legislation might affect the electronic circulation of information [45].

The fourth theme that appears regularly in information science journals involves the general area of theoretical and quantitative studies. In the earlier decades of our period, a number of attempts were made - not least in the UK - to devise a general framework for the understanding of information science [46]. Much of this work was based on the hope that quantitative studies of information flow would help provide generalisations of use to information scientists [47]. One of the terms that came to be used for such studies - bibliometrics - was actually coined in the UK [48], though it has now been partly superseded by terms seen as having broader applicability, such as scientometrics. An obvious example of a quantitative law - described first in the UK - is Bradford's law of scattering, which originated well before our 50-year period [49]. Much of the early running in the field of bibliometrics was made in the United States, and that country has remained the main focus of such work ever since (though the Soviet Union made important early contributions, and bibliometric research now has a world-wide basis). Within the UK, interest in bibliometric studies grew during the 1960s and 1970s, but then diminished, only to grow again in recent years. One area where the UK made a useful contribution in the earlier period was in the discussion of how literature usage declined with its age, how the change might best be measured, and the implications for librarians and information scientists [50]. More recently, the emphasis in the UK has been on how to measure the relative importance of different authors, papers, or journals. A major driving force for this has been the wish to shift comparisons in the Research Assessment Exercise [RAE] towards a metrics-based approach. This has led to a number of innovative studies, with a particular interest in research which looks at ways of ensuring that different authors or subjects are compared equitably [51]. Amongst all this activity, researchers have, of course, cast a beady eye on the RAE and the metrics of information science, itself [52].

\section{Factors affecting information science research in the UK}

One obvious influence on the development of information science research, in the UK as elsewhere, has been the availability of funding. When the existing Department of Scientific and Industrial Research [DSIR] was split up in the mid-1960s, one of the new bodies formed from it was the Office for Scientific and Technical Information [OSTI]. Senior scientists at the time were worried by the ever-expanding flood of scientific information, and saw the need for centrally funded support to study the problems that it caused. This sort of question was, of 


\section{Jack Meadows}

course, meat and drink to the newly named group of information scientists, and some soon obtained grants from the new body. OSTI, itself, recognised that the research community at which they aimed was limited in its numbers. This led them, on the one hand, to encourage new researchers and, on the other, to map out their own view of what topics were of prime importance. They recognised early on that computer-based handling of information was going to be a vital area for research, and, by the 1970s, had extended this to include networking. In the mid-1970s, OSTI was absorbed into the newly formed British Library, and its name was changed to the British Library Research and Development Department [BLRDD]. OSTI had always supported some library research and also some research in the social sciences. In its new guise, the funding agency covered all subjects, including the humanities.

But the research community remained small. The Department complained in the 1970s that new teams of researchers were slow to appear - much of the work was being done by people who had already been involved in the 1960s. This changed over the next two decades, though several of the early comers continued to figure prominently in the grants list. The Department's contribution to supporting research was essential. For example, an analysis of the period 19781985 found that nearly half of the funding for research in library and information science in the UK came from BLRDD [53]. The Department always took a proactive approach to funding, in part because of the limited number of researchers in the field, and many of the projects it supported had a practical orientation. Over the past 25 years, government policy has been increasingly to emphasize both these aspects for all research. By the 1990s, this was reflected in BLRDD support for research. The Department had always been willing both to consider projects proposed from outside, and to support work with no near-future application. Such dispensations now became rarer. At the same time, projects became shorter in duration. Earlier grants might be awarded for periods of 2-3 years to allow in-depth exploration. Now projects might last for only half a year. In 1996, BLRDD suffered a name change and subsequently underwent a confusing series of transformations [54]. The overall result was that the amount of funding for information science research went down, and the degree of central direction of the research went up.

Though bodies such as the Arts and Humanities Research Council have provided some funds for research of interest to information science, their scope has often been limited. Of more general interest has been the Joint Information Systems Committee [JISC], which was established in 1993 to deal with networking and specialist information services for further and higher education in the UK. To this end, it developed a series of strategies, and commissioned research to support these. JISC has the virtue of good financial backing: the drawbacks are that it decides what projects are to be done, and, as the frequent use of the word 'deliverables' implies, the research is targeted at applicable results. Perhaps for this reason, JISC funding is typically excluded from the research monies submitted for the RAE. The overall outcome has been that, though funding for information science in the UK has risen again in recent years, it is now allocated via a more top-down approach than in earlier years. One spin-off from the emphasis on strategy has been a growth of activity in information policy research. This is now a matter of continuing interest in British information research [55]. For some years past, the European Commission has funded projects of interest to information scientists (initially via DG XIII), and these, too, have often emphasised policy matters. As with JISC, the nature of such 


\section{Jack Meadows}

projects is decided on by the Commission, but, in this case, cooperation with colleagues within the European Community is an especially important factor. Despite their limitations, both JISC and EC projects have produced research whose value is not restricted solely to immediate applications.

Research in information science in the UK has particularly thrived in universities. BLRDD research grants to institutions of higher education usually exceeded both in number and amount the grants that it allocated to all other bodies put together. Information science was one area where the old polytechnics could compete with the traditional universities, but, prior to their reestablishment as new universities in the 1990s, they mainly concentrated on teaching. Though this has now changed - not least as a result of the RAE - it is probably fair to say that the major research centres for information science have always been situated predominantly in the older universities. The impact of the RAE on research in information science at the universities has been a matter for continuing comment [56]. It is generally felt that the process has increased the emphasis on research in departments, but has also increased the time wasted on bureaucracy. The hope must be that the former can be retained, while the latter can be decreased in future such exercises. But basic questions remain unanswered. For example, will departments that receive little or no income as a result of the RAE eventually give up on research, or will it stimulate them to enhance their research efforts? As part of their research activities, departments have, for many years, established research centres to deal with particular areas of information science. One major centre, however, lay outside the university network. For three decades from 1959 onwards the Aslib Research and Consultancy Department was a major contributor to the development of research in the subject both nationally and internationally. Its main interests lay in the evaluation of operations, user studies and automation [57], and a number of the research projects carried out were of long-term interest. For example, a survey of the information-gathering habits of scientists carried out first in the 1960s was repeated in the 1980s and showed that significant changes had occurred [58]. At the other end of the spectrum, the Department was closely involved in the introduction of teletext - in the form of Prestel - in the UK. The final closure of the Department by Aslib was therefore a blow for UK research, even though, by that time, the consultancy side had begun to dominate the research side. The growth of tendering for specified projects that has developed over the past two decades has certainly encouraged consultancy work: an area in which the UK previously lagged well behind the USA. For smaller consultancy teams, JISC is the more important target for funds. The European Commission requires both continuing contact and the cooperation of institutions in different member states. This, along with the much higher level of bureaucracy, tends to favour larger teams. From the research viewpoint, consultancy work has the drawback that the results may not be published via the usual quality-controlled channels.

The Aslib Research and Consultancy Department led the field in another way - the creation of research centres covering particular areas of information science. Most of the centres created over the past few decades have been situated in universities, and have typically reflected the interests of leading researchers in the departments concerned. Such centres have the virtue not only of providing a national focus for particular kinds of research, but also of providing an element of continuity over a period of years. On the down side, centres tend to have up-anddown careers as project heads leave, sponsors switch their funding, and, not least, the research 


\section{Jack Meadows}

specialism itself changes. For example, a programme of catalogue research was set up at Bath University towards the end of the 1970s, which subsequently transmuted into a centre for such research. In the 1980s, mainly due to the impact of information technology, this was renamed the Centre for Bibliographic Management. At the end of the 1980s, a UK Office for Library Networking was also set up at Bath, and, in the 1990s, the two merged to form a new centre the UK Office for Library and Information Networking [UKOLN]. Another example is the Centre for Library and Information Management [CLAIM]. Originally at Cambridge University (under a different name), it moved to Loughborough University in the mid-1970s. It was decided to disband it in the mid-1980s, but one part of its activities - statistics - had proved particularly valuable both at home and abroad. After representations, not least from the American Library Association [ALA], it was decided to continue this work by establishing a smaller centre at Loughborough, entitled the Library and Information Statistics Unit [LISU], which still exists. As the last story suggests, one of the virtues of setting up research centres is that they often receive attention from outside the UK as well as from within.

Interaction with information scientists in other countries has always been important. Membership of the EC has been valuable in promoting greater contact within Europe. But the yardstick for measuring research excellence in information science has always been the United States. Comparison of developments in the UK and the USA is difficult because of the differing sizes of the research communities and of the amount of funding available. It does seem, however, that the organisational arrangements in the UK have sometimes been more beneficial than those in the USA. An obvious example relates to the provision of funding. The USA has never had a funding body comparable with BLRDD (nor, indeed, has any other country). Instead, US information scientists have had to seek funds from a range of sources. The National Science Foundation [NSF], for example, has concerned itself with scientific information and with its computer-based handling over the past half-century. But the NSF has blown hot and cold on the topic during this time, producing corresponding ups and downs in the research it supports. Overall, BLRDD managed to provide a higher level of consistency and continuity in its funding provision. Or, to take a different example - the relationship between the information science world and the library world in the two countries. An important factor in the creation of the Institute of Information Scientists [IIS] was disagreement with the Library Association [LA] over training needs. Yet, in subsequent decades, the LA proved increasingly flexible in accepting greater amounts of information science into the curricula that they validated. The result has been a reasonably harmonious development of library and information teaching and research in the UK. The end result of this growing together was the combination of the IIS and the LA into the Chartered Institute of Library and Information Professionals [CILIP]. In the USA, the American Library Association was for some time considerably less inclined to accept large amounts of information science into the curriculum. This made the development of curricula more difficult, and, with the decline in the number of US university library departments, also affected research. But, although the organisation of information science in the UK may have had some advantages, the greater amount of funding and greater number of personnel in the USA have ensured that research in information science carried out there has been of dominant importance throughout the world over the past 50 years. 


\section{Jack Meadows}

In discussing research themes, I mentioned international recognition as an important selection factor. The simplest way of assessing such influence is via citation studies, not least in terms of citations of UK research papers by authors in the USA. A citation study carried out at the end of the 1990s produced a map of what, it was suggested, were the most significant 75 names in information research over the period 1972-1995 [59]. Most - as might be expected were North American, but 12 were British (and another four carried out their earlier work in the UK). In view of the difference in the sizes of the research communities in the US and the UK, this suggests that British research in information science has pulled its weight in the past 50 years. British involvement was, perhaps, particularly important early on, since 'information science' was accepted as a designation in the UK before it became generally accepted in the USA. Thus the American Documentation Institute changed its name to the American Society for Information Science in 1968 - ten years after the formation of the IIS in the UK.

Looking back over the past 50 years, one conclusion must be that past research in information science is now paying off. Activities that were relatively marginal decades ago such as automated information retrieval - are now at the heart of major growth industries. Although this has attracted greater funding support, projects nowadays are often more narrowly focused than in the past. 'Blue skies' research may actually be more difficult to sustain now. This tendency is emphasised by the pressures on researchers in universities to give more attention to applicable research. The widening interest in information science research has also brought in researchers from other disciplines - not least computer specialists. The growing influence of these latter can readily be traced in information science jargon. For example, 'metadata' was a rare term in the subject twenty years ago, but now it is universal. Nor are computer specialists alone in spreading into traditional areas of information science: business and management researchers are also becoming increasingly involved. Both computer studies and business studies are much larger than information science in terms of number of researchers and of financial support. Consequently, this merging of interests is also, to some extent, a submerging, as can be seen in some of the departmental reorganisations at universities in the UK. The term 'informatics' - formerly regarded with suspicion in the UK - is now coming into favour as a description of this blending. The overall result is that the information science activities developed over the past 50 years have triumphed, but information science as a separate entity may be on the wane. If so, its final epitaph might well be that of Sir Christopher Wren in St. Paul's Cathedral - 'If you want a monument, look around you'.

\section{Acknowledgements}

My thanks go to Brian Vickery for his comments on this article, and to John Martyn for supplying information. I would also like to thank the referees for their suggestions. 


\section{Jack Meadows}

\section{References}

[1] A. Black, D. Muddiman and H. Plant Information management in Britain before the computer Ashgate, Aldershot; 2007

[2] K. Jarvelin and P. Vakkari 'The evolution of information science 1965-1985: a content analysis of journal articles’ In: P. Vakkari and B. Cronin (eds.) Conceptions of library and information science Taylor Graham, London; 1992

[3] C.W. Cleverdon The effect of variations in relevance assessments in comparative experimental tests of index languages Cranfield Institute of Technology, Cranfield;1970

[4] K. Sparck Jones and C.J. van Rijsbergen 'Information retrieval test collections’ Journal of Documentation 32, 59-75 (1976)

[5] A.F. Smeaton and D. Harman 'The TREC experiments and their impact on Europe' Journal of Information Science 23, 169-174 (1997)

[6] B.C.Vickery Retrieval system theory Butterworths, London; 1961

[7] K. Sparck Jones Automatic keyword classification for information retrieval Butterworths, London; 1971

[8] C.J. van Rijsbergen Information retrieval Butterworths, London; 1979

[9] S.C. Bradford Documentation Crosby Lockwood, London; 1948

[10] R.A. Fairthorne Book review Journal of Documentation 18, 196-198 (1962)

[11] K. Sparck Jones 'A statistical interpretation of term specificity and its application to retrieval' Journal of Documentation 28, 11-21 (1972)

[12] N. Jardine and C.J. van Rijsbergen 'The use of hierarchic clustering in information retrieval’ Information Storage and Retrieval 7, 217-240 (1971)

[13] S.E. Robertson 'The probability ranking principle in IR' Journal of Documentation 33, 294-304 (1977)

[14] S.E. Robertson 'Overview of the Okapi projects’ Journal of Documentation 53, 3-7 (1997)

[15] M. Beaulieu 'Interaction in information searching and retrieval' Journal of Documentation 56, 431-439 (2000)

[16] N. Bishop, V.J. Gillet, J.D. Holiday and P. Willett 'Chemoinformatics research at the University of Sheffield: a history and citation analysis’ Journal of Information Science 29, 249-267 (2003)

[17] A. Gilchrist The thesaurus in retrieval Aslib, London; 1971

[18] J.F.B. Rowland 'The scientist's view of his information system' Journal of Documentation 38, 38-42 (1982)

[19] J.M. Brittain Information and its users Bath University Press, Bath; 1970

[20] M.B. Line 'The information uses and needs of social scientists: an overview of INFROSS' Aslib Proceedings 23, 412-434 (1971)

[21] D.R. Streatfield and T.D. Wilson 'Information innovations in social services: a third report on project INISS’ Journal of Documentation 38, 273-281 (1982)

[22] D. Nicholas, P. Huntington and A. Watkinson 'Scholarly journal usage: the results of deep log analysis' Journal of Documentation 61, 248-280 (2005)

[23] N. Moore 'Developing the use of a neglected resource: the growth of information management' Journal of Information Science 15, 67-70 (1989)

[24] K.A. Streetman 'Information research in Europe: an investigation’ Journal of Information Science 19, 149154 (1993)

[25] T.D. Wilson 'The nonsense of knowledge management' Information Research 8, Paper No. 144 (2002) [http://informationr.net/ir/8-1/paper144.html] 


\section{Jack Meadows}

[26] A. Jashapara Knowledge management: an integrated approach Pearson Education, Harlow; 2004

[27] P.B. Checkland and J.Scholes Soft systems methodology in action John Wiley and Sons, Chichester; 1990

[28] T.D. Wilson 'On user studies and information needs’ Journal of Documentation 37, 3-15 (1981)

[29] N.J. Belkin, R.N. Oddy and H.M. Brooks ‘ASK for information retrieval’ Journal of Documentation 38, 6171 and 145-164 (1982)

[30] D. Ellis ‘A behavioural model for information retrieval system design’ Journal of Information Science 15, 237-247 (1989)

[31] B.C. Vickery and A. Vickery 'Online search interface design’ Journal of Documentation 49, 103-187 (1993)

[32] F. Wood, N. Ford, D. Miller, G. Sobczyk and R. Duffin 'Information skills, searching behaviour and cognitive styles for student-centred learning: a computer-assisted learning approach’ Journal of Information Science 22, 79-92 (1996)

[33] M. Beaulieu and C.L. Borgman 'A new era for OPAC research: introduction to special topic issue on current research in online public access systems' Journal of the American Society for Information Science 47, 491-492 (1996)

[34] C.L. Borgman 'Digital libraries and the continuum of scholarly communication' Journal of Documentation 56, 412-430 (2000)

[35] A.J. Meadows Communication in science Butterworths, London; 1974

[36] C. Cherry On human communication MIT Press, Cambridge, Mass.;1957

[37] B. Cronin 'Invisible colleges and information transfer' Journal of Documentation 38, 212-236 (1982)

[38] M.D. Gordon 'The roles of referees in scientific communication’ In: J. Hartley (ed.) Technology and writing: readings in the psychology of written communication Jessica Kingsley, London; 1992 pp. 263-275

[39] A.J. Meadows Communicating research Academic Press, San Diego; 1998 pp. 177-199

[40] B. Shackel, D.J. Pullinger, T.I. Maude and W.P. Dodd 'The BLEND-LINC Project on “electronic journals” after two years' Computer Journal 26, 247-254 (1983)

[41] F. Rowland, C. McKnight and J. Meadows Project ELVYN: an experiment in electronic journal delivery Bowker Saur, London; 1995

[42] D. Nicholas, P. Huntington and H.R. Jamali 'The impact of open access publishing (and other access initiatives) on use and users of digital scholarly journals’ Learned Publishing 20, 11-15 (2007)

[43] www.ecs.soton.ac.uk/ harnad/

[44] E. Gadd, C. Oppenheim and S. Probets 'RoMEO studies 1: the impact of copyright ownership on academic author self-archiving’ Journal of Documentation 59, 243-277 (2003)

[45] C. Oppenheim 'Does copyright have any future on the internet?' Journal of Documentation 56, 279-296 (2000)

[46] B.C. Brookes 'The foundations of information science: Part I’ Journal of Information Science 2, 125-133 (1980)

[47] R.A. Fairthorne 'Empirical hyperbolic distributions (Bradford-Zipf-Mandelbrot) for bibliometric description and prediction’ Journal of Documentation 25, 319-343 (1969)

[48] A. Pritchard 'Statistical bibliography or bibliometrics' Journal of Documentation 25, 348-349 (1969)

[49] B.C. Vickery 'Bradford’s law of scattering’ Journal of Documentation 4, 198-203 (1948)

[50] M.B. Line and A. Sandison 'Practical interpretation of citation and library use studies' College and Research Libraries 36, 393-396 (1975)

[51] I. Rowlands 'Journal diffusion factors: a new approach to measuring research influence’ Aslib Proceedings 54, 77-84 (2002) 


\section{Jack Meadows}

[52] A. Holmes and C. Oppenheim 'Use of citation analysis to predict the outcome of the 2001 RAE for Unit of Assessment 61: Library and Information Management’ Information Research 6 (2001) [http://www.shef.ac.uk/ is/publications/infres/6-2/paper103.html]

[53] J. Meadows Innovation in information: twenty years of the British Library Research and Development Department Bowker Saur, London; 1994 p.151

[54] A. Goulding 'Searching for a research agenda for the library and science community' Journal of Librarianship and Information Science 39, 123-125 (2007)

[55] I. Rowlands (ed.) Understanding information policy Bowker Saur, London; 1997

[56] J. Elkin and D. Law 'The 1996 Research Assessment Exercise: the Library and Information Management Panel' Journal of Librarianship and Information Science 29, 131-141 (1997)

[57] A. Gilchrist, J. Martyn and P. Vickers 'Jumping through skylights: recollections of the Aslib Research and Consultancy Department’ Managing information 6, 31 (December 1999)

[58] J. Martyn Literature searching habits and attitudes of research scientists British Library Research Paper No. 14 British Library, London; 1986

[59] H.D. White and K.W. McCain 'Visualising a discipline: and author co-citation analysis of information science’ Journal of the American Society for Information Science 29, 327-355 (1998) 